\title{
Correction: Gao, Y., et al. Application of NSGA-II and Improved Risk Decision Method for Integrated Water Resources Management of Malian River Basin. Water 2019, 11, 1650
}

\author{
Yayu Gao ${ }^{1,2,3, * \mathbb{D}}$, Xinmin Zhang ${ }^{4}$, Xiaoyou Zhang ${ }^{1,2}$, Duan Li $^{1,2}$, Min Yang ${ }^{2,5}$ (D) and \\ Jinhua $\operatorname{Tian}^{3}$ \\ 1 Key Laboratory of Eco-hydrology of Inland River Basin, Northwest Institute of Eco-Environment and \\ Resources, Chinese Academy of Sciences, Lanzhou 730000, China; zhangxy@lzb.ac.cn (X.Z.); \\ liduan@lzb.ac.cn (D.L.) \\ 2 University of Chinese Academy of Sciences, Beijing 100049, China; yangmin182@mails.ucas.ac.cn \\ 3 Gansu Provincial Soil and Water Conservation Research Institute, Lanzhou 730000, China; tjhgyy@yeah.net \\ 4 Gansu Provincial Water Science Research Institute, Lanzhou 730000, China; xmzhgs@aliyun.com \\ 5 State Key Laboratory of Cryospheric Science, Northwest Institute of Eco-Environment and Resources, \\ Chinese Academy of Sciences, Lanzhou 730000, China \\ * Correspondence: gaoyayu18@mails.ucas.ac.cn
}

Received: 27 August 2020; Accepted: 27 August 2020; Published: 10 September 2020

In the published article [1], the authors realized some errors in the second affiliation and thus wish to make the revisions as below:

1. Change the Affiliation 2 "Chinese Academy of Sciences, Beijing 100049, China" to "University of Chinese Academy of Sciences, Beijing 100049, China".

The authors would like to apologize for any inconvenience caused to the readers by the change. The change does not affect the scientific results. The manuscript will be updated, and the original will remain online on the article webpage, with a reference to this correction.

\section{References}

1. Gao, Y.; Zhang, X.; Zhang, X.; Li, D.; Yang, M.; Tian, J. Application of NSGA-II and Improved Risk Decision Method for Integrated Water Resources Management of Malian River Basin. Water 2019, 11, 1650. [CrossRef]

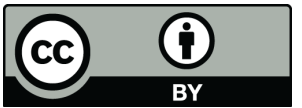

(C) 2020 by the authors. Licensee MDPI, Basel, Switzerland. This article is an open access article distributed under the terms and conditions of the Creative Commons Attribution (CC BY) license (http://creativecommons.org/licenses/by/4.0/). 